\title{
Characteristics and management of chronic destructive pneumonia
}

\author{
E W J CAMERON, P C APPELBAUM, D PUDIFIN, W S HUTTON, S A CHATTERTON, \\ AND J DUURSMA
}

From the Departments of Thoracic Surgery, Microbiology, and Medicine, University of Natal, Durban, South Africa

ABSTRACT In 12 years 627 patients presented to Wentworth Hospital, Natal with chronic destructive pneumonia (CDP). Common symptoms were haemoptysis, the production of foul-smelling sputum, and chest pain. The disease pursued a chronic course with acute exacerbations which may be lethal. The majority of patients were African men aged between 20 and 50 years who were free 3 from other significant disease apart from dental infection. Radiographically and pathologically CDP had the characteristics of a necrotising pneumonia, and microbiological investigation showed $\vec{\bullet}$ mixed aerobic and anaerobic flora in the lower respiratory tract. Gram-positive aerobic cocci ando Bacteroides species were the predominant organisms. In 120 patients treatment regimens were based on chloramphenicol, in 429 cephalosporins, and in 78 on combination therapy with cephalosporins, penicillin, and metronidazole. One hundred and seventy patients also required operative management in an attempt to control progress of the disease. The overall inpatient mortality rate from CDPڤ was $7 \cdot 8 \%$. In the group of patients treated with combination therapy the mortality rate was $1 \cdot 3 \% \cdot \stackrel{\circ}{\Omega}$

Le Roux ${ }^{1}$ introduced the term "chronic destructive pneumonia" (CDP) when describing a pulmonary lesion which occurs in Natal, South Africa. The disease has the characteristics of a bacterial infection and its pathological hallmark is necrosis of pulmonary tissue.

Between 1966 and 19'77, 627 patients with CDP were referred to the Thoracic Surgical Unit, Wentworth Hospital from medical clinics where the natural history of the disease had been modified by antimicrobial therapy. The common reason for referral of the patients was failure of such therapy to control the disease. In this paper we summarise the characteristics and management of CDP in this group of patients, of whom $75 \%$ were African men aged between 21 and 60 years.

\section{Clinical features}

The cardinal symptoms of CDP are haemoptysis, cough productive of foul-smelling sputum, and chest pain. Fifteen per cent of patients had a history shorter than one month. Their symptoms

Address for reprint requests: Mr EWJ Cameron, Department of Thoracic Surgery, City Hospital, Greenbank Drive, Edinburgh. were acute in onset and life-threatening in severity. Forty-seven per cent of patients had ao history of more than one acute episode of pulmonary infection treated at a medical clinic.으 Some patients had experienced up to five recur- $\frac{\overrightarrow{0}}{x}$ rences of acute illness with intervening periodso of quiescence and wellbeing. However, many of $\stackrel{3}{3}$. these patients eventually developed symptoms refractory to medical therapy. Thirty-two per cent of patients were referred from tuberculosiso clinics where failure to isolate mycobacteria and lack of response to chemotherapy prompted을 review of the original diagnosis of pulmonary tuberculosis. Six per cent of patients were thoughto to have bronchial carcinoma. The symptom- N atology in the last two groups of patients was chronic and undramatic. Significant other disease, 0 most commonly grand mal epilepsy and diabetes mellitus, coexisted with CDP in $6 \%$ of patients. $\frac{\bar{D}}{\Phi}$

The family and social histories of the patients $\stackrel{\infty}{+}$ showed the disease to be endemic throughout 0 urban and rural Natal. Among the men overö 21 years of age ( $88 \%$ of all patients) spree drinking and cigarette smoking were prevalent habits.

On admission to Wentworth Hospital $18 \%$ of $\frac{\varrho}{\sigma}$ patients were in extremis; of the remainder half were febrile and ill and half were clinicallyo 
undisturbed. On examination the pertinent findings included severe dental caries, gingivitis, or pyorrhoea in $60 \%$ and finger clubbing in $40 \%$ of patients. Almost all patients had clinical signs in their chests. Evidence of high alcohol consumption was seen in a number of patients who had patchy depigmentation of the lips, but other evidence of vitamin deficiency or malnutrition was rare.

\section{Radiography}

The radiographic appearance of CDP is variable. The lesions are single, circumscribed, and rarely lobar or segmental in shape. Chronic destructive pneumonia may present as a uniform opacity (figs 1,2 ), or may show more difuse shadowing, frequently becoming cavitated, usually with multiple loculi (figs 3 , 4). The chest radiograph does not return to normal after CDP has become clinically quiescent. Residual dense linear opacities are evidence of a healed lesion.

Bronchography was carried out in $88 \%$ of patients. Bronchial distortion and displacement were delineated and the almost inevitable sequelae of CDP were bronchiectasis and destruction of pulmonary tissue and bronchi by cavitation.

In this series CDP originated in the right upper lobe in $30 \%$ of patients, in the left upper lobe in $13 \%$, and in the lower lobar apical segments in $12 \%$. When the disease recurred it was at the site of the original lesion.

\section{Microbiology}

The microbiology of CDP was investigated in 50 consecutive cases. Specimens were collected by

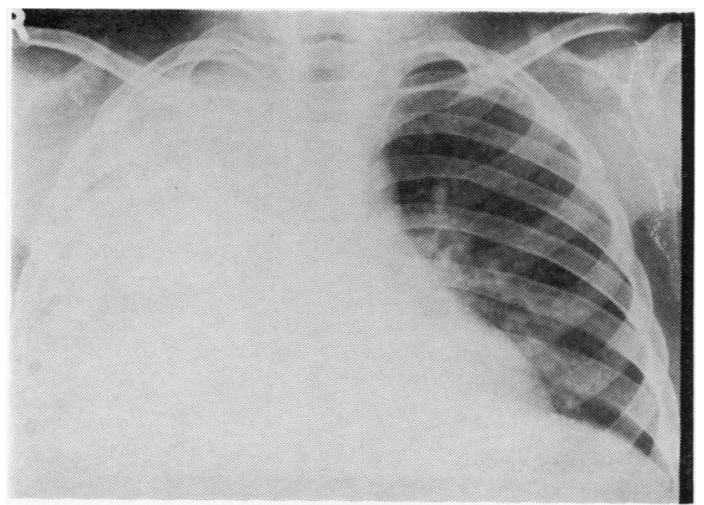

Fig 1 Postero-anterior chest radiograph of a child aged 6 years with medically uncontrolled CDP involving the entire right lung.

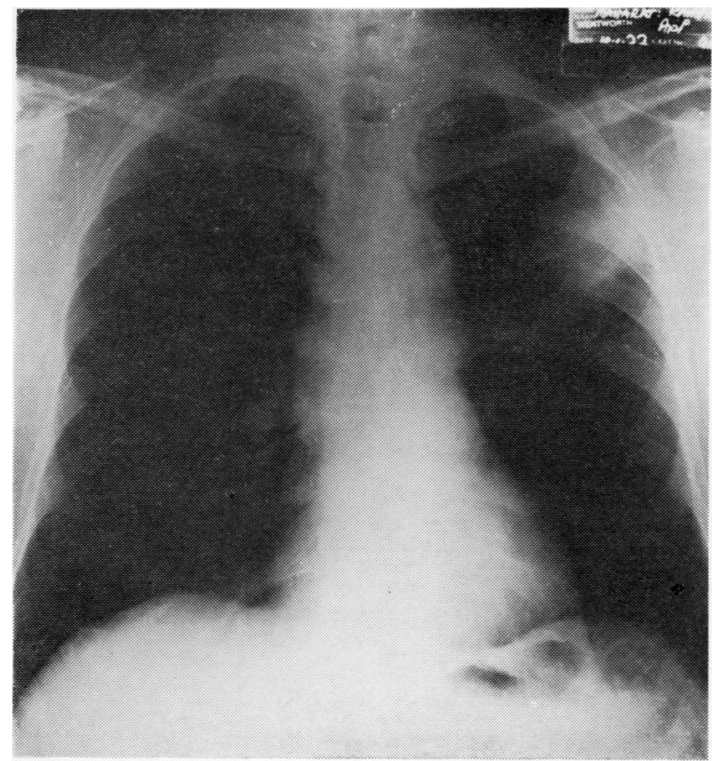

Fig 2 Postero-anterior chest radiograph of Indian man aged 63 years. The lesion in the left upper zone was uniformly opaque on tomography. The patient was asymptomatic, edentulous, teetotal, and a non-smoker. The preoperative diagnosis was bronchial carcinoma.

invasive methods-percutaneous lung puncture, transtracheal aspiration, and open lung biopsyand were processed by aerobic and anaerobic techniques. ${ }^{2}$ The results are set out in table 1 .

In 27 of the 50 patients both aerobes and anaerobes were recovered, aerobes only in 13, anaerobes only in three, and isolates were sterile in seven. In six patients putrid specimens were obtained but there was a failure to recover anaerobes. If putrid odour is taken to be pathognomic of anaerobic infection ${ }^{3}$ cultural or clinical evidence of anaerobic infection was found in 36 patients.

Sputum specimens from each patient were examined concurrently for aerobic bacteria and fungi. The bacteria isolated from the sputum were similar to those found on invasive sampling in 11 of the 50 patients; in the others cultures of sputum were sterile or yielded species absent from the invasive samples.

All patients had at least six consecutive daily sputum samples examined by direct smear and concentration techniques and by culture for mycobacteria. Trap specimens were also taken at bronchoscopy with a MacRae mucus extractor. Mycobacteria were not isolated. 


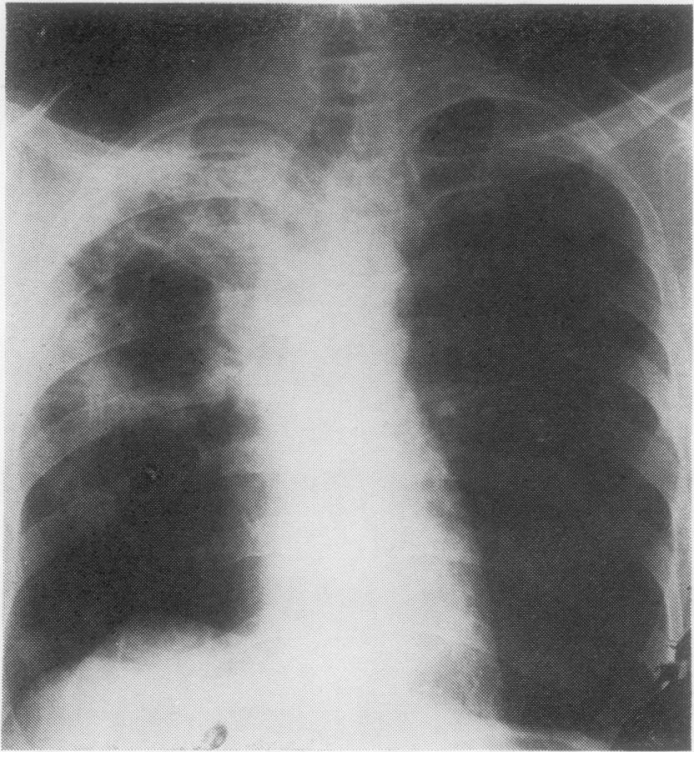

Fig 3 Postero-anterior chest radiograph taken on the third admission for CDP of a 46-year-old Indian man known to be a heavy drinker. On examination he had pyorrhoea and finger clubbing. While on medical treatment he developed massive haemoptysis.

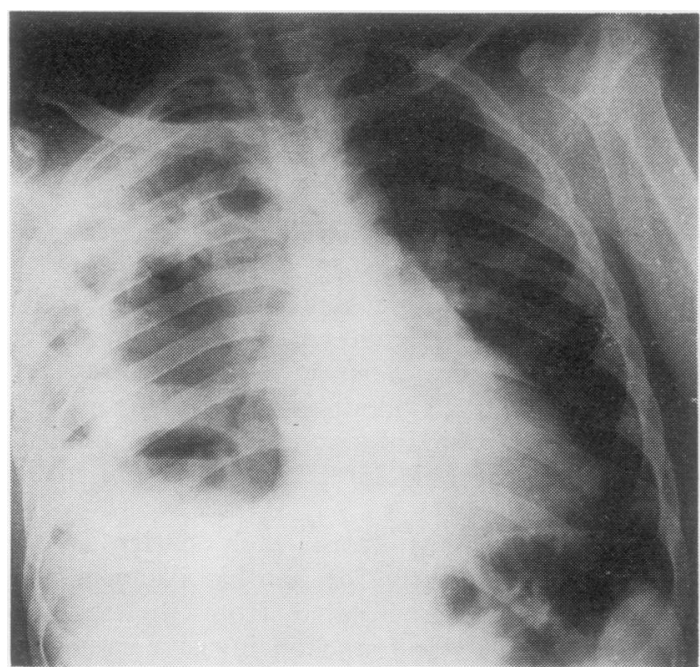

Fig 4 Typical postero-anterior chest radiograph of clinically acute (pathologically "active") CDP of the right lung. Multiple cavities are seen, some containing fluid levels.

\section{Pathology}

The description of the gross and microscopic pathology of CDP is based on examination of the
Table 1 Organisms recovered by invasive sampling

\begin{tabular}{lll}
\hline Type of organism & Number of patients \\
\hline Aerobes & 20 \\
Streptococcus viridans & 11 \\
Streptococcus faecalis & 8 \\
Streptococcus haemolyticus & 5 \\
Streptococcus other subspecies & 10 \\
Staphylococcus epidermidis & 6 & \\
Staphylococcus aureus & 13 & \\
Enterabacteria & 9 & \\
Haemophilus species & 8 & \\
Others & 11 & \\
Anaerobes & 19 & \\
Bacteroides melaninogenicus & 14 \\
Bacteroides other subspecies & 3 & \\
Others & & \\
Fungi & & \\
Candida & &
\end{tabular}

operative specimens from 158 patients, and on the necropsy findings in five patients who died 3 during medical treatment.

The pleurae covering the lesion were fused, $\vec{\theta}$ thickened, and fibrotic yet highly vascularised $\infty$ (fig 5) by blood vessels derived from the parietes and the lung. Pleural effusion and secondary empyema thoracis have not been encountered.

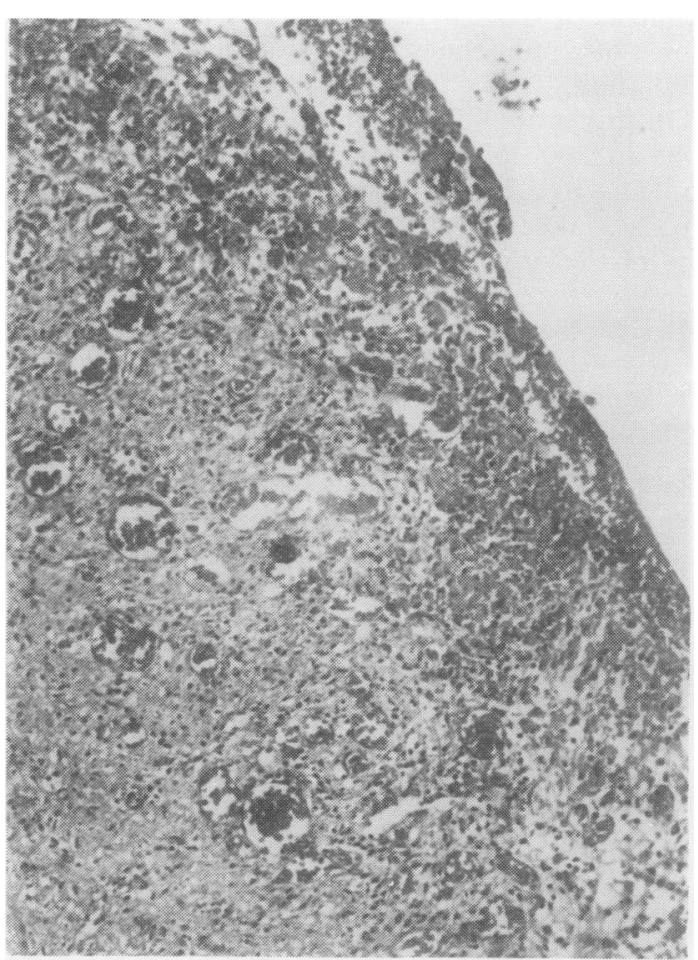

Fig 5 Vascular pleura from specimen shown in fig 6. Haematoxylin and eosin, original magnification $\times 25$. 


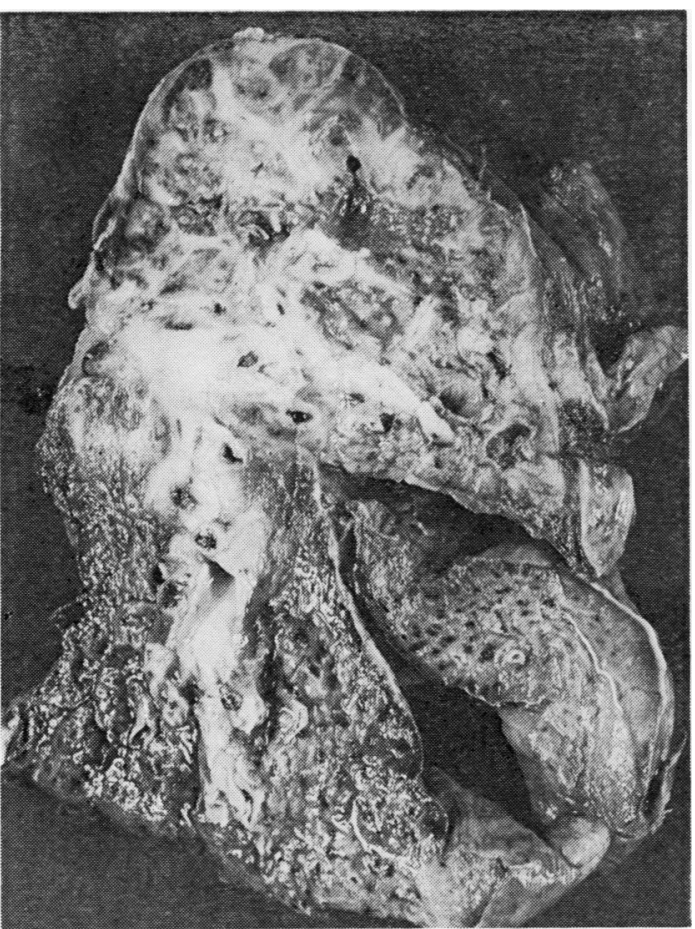

Fig 6 Resected specimen of right lung shown in fig 3. There is "active" cavitating CDP in the upper lobe. There is "inactive" disease in the apical and posterior segments of the lower lobe with healing by fibrosis and obliteration of the posterior part of the oblique fissure. The overlying pleura is thickened. $S$ viridans, Proteus morganii and Bacteroides melaninogenicus ss intermedius were isolated.

The lung in CDP was airless and where the lesion had invaded a neighbouring lobe the confluent inflammatory mass obliterated all trace of the interlobar fissure (fig 6). The pulmonary and bronchial lesions in clinically acute and quiescent CDP are summarised in table 2. It is usual to find areas of "active" and "inactive" disease juxtaposed in CDP parenchyma with one or the other type of lesion dominant (figs 6,7). As in bronchiectasis $^{4}$ there is enlargement of the bronchial arteries supplying the affected lung, but the striking histopathological feature of the pulmonary blood vessels surviving in an active lesion is obliteration of the lumen.

\section{Immunology}

An assessment of immunological function was undertaken in a consecutive series of 20 African men aged from 20 to 50 years. The results were compared with those of a control group of healthy African men of similar age range. The tests used were total lymphocyte counts and $T$ and B lymphocyte counts, ${ }^{5}$ assays of immunoglobulins $\mathbf{G}, \mathbf{A}$, and $\mathbf{M}$, and of $\mathrm{C} 3$ by means of standard radial immunodiffusion technique, and lymphocyte response to stimulation by the mitogen PHA. ${ }^{6}$

All patients had normal or somewhat increased numbers of circulating lymphocytes (mean 3517 cells $/ \mathrm{mm}^{3}$, range $1512-5830$ cells $/ \mathrm{mm}^{3}$ ). Proportions of T, B, null, and "double marker" lymphocytes were normal. No instance of impaired ability to produce antibody was found, all patients having normal or raised levels of IgG, IgA, and IgM. C3 levels were normal. T lymphocyte formation was impaired in six of the 20 patients with tritiated thymidine uptakes between $20 \%$ and $40 \%$ of the normal control value.

\section{Management}

The antibiotic regimens used in the management of CDP altered during the 12 years of this study. From 1966 to 1969 the regimen was based on chloramphenicol, and from 1969 to 1976 on cephalosporins. If indicated by isolation of particular sputum pathogens other antibiotics were also given. In order of frequency they were the penicillins, aminoglycosides, sulphonamides, and tetracyclines. Forty per cent of patients also had antituberculosis chemotherapy. Between 1976 and 1977 a combination of cephalosporin, penicillin, and metronidazole was standard therapy. The drug regimens are given in table 3 .

Table 2 Pathology of CDP

\begin{tabular}{llll}
\hline Classification & Tissue & Gross pathology & Histopathology \\
\hline Active & Lung & $\begin{array}{l}\text { Consolidated lung containing pus and slough- } \\
\text { filled cavities } \\
\text { Purulent bronchitis }\end{array}$ & $\begin{array}{l}\text { Exudative pneumonia with alveolar necrosis and } \\
\text { cavitation limited by pyogenic membrane } \\
\text { Acute bronchitis with mucosal ulceration in the } \\
\text { draining bronchi and bronchial destruction in the } \\
\text { CDP lesion }\end{array}$ \\
Inactive & Lung & $\begin{array}{l}\text { Fibrous replacement of lung tissue containing } \\
\text { residual cavities lined by granulation tissue } \\
\text { Bronchiectasis }\end{array}$ & $\begin{array}{l}\text { Fibrosis of cavity walls and organising pneumonia } \\
\text { Bronchi }\end{array}$ \\
& & & $\begin{array}{l}\text { Follicular bronchiectasis with peribronchial fibrosis } \\
\text { and epithelial metaplasia }\end{array}$ \\
\hline
\end{tabular}




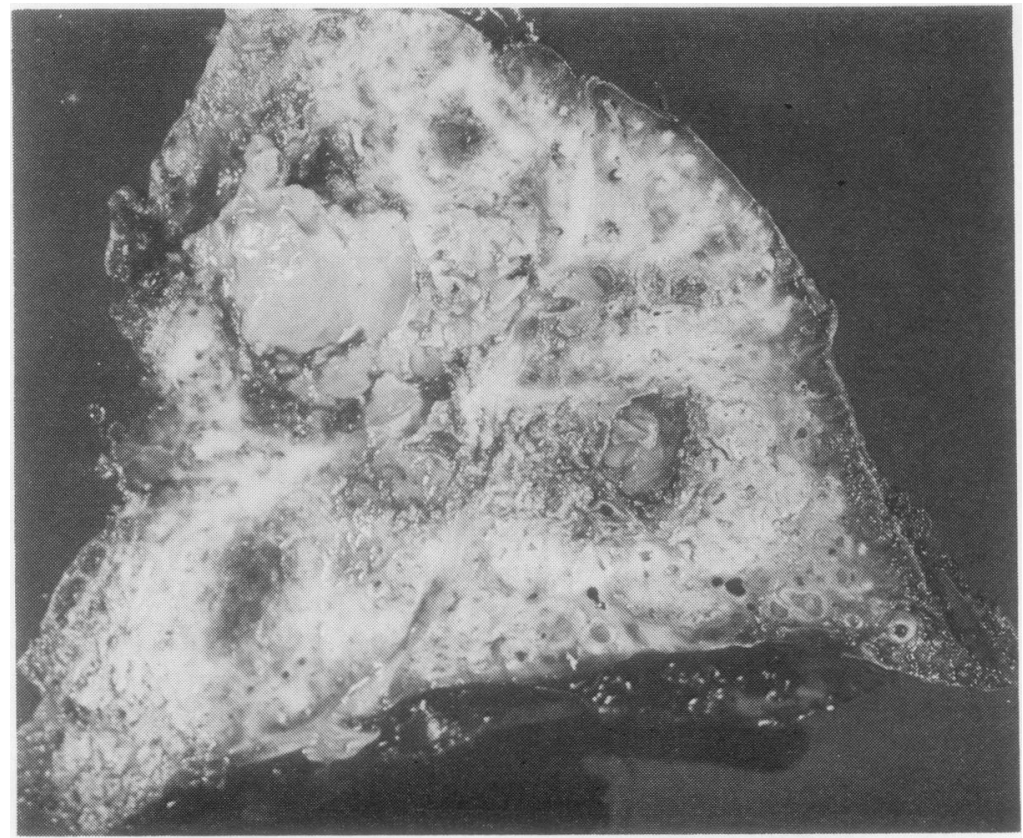

Fig 7 Resected specimen of right lung shown in fig 1 . Large volumes of lung slough are evident. Haemophilus influenzae, Neisseria catarrhalis and Bacteroides melaninogenicus ss asaccharolyticus were isolated.

In general the drugs were given in high dose to inpatients who were severely ill (patients presenting with massive haemoptysis or uncontrolled pulmonary suppuration or both) or as cover therapy to patients submitted to operation. Low dose oral therapy was given to the other inpatients and to outpatients who remained on maintenance therapy until there was radiographic as well as clinical evidence of healing.

Chest physiotherapy was routine treatment for all hospital patients with CDP.

The decision to operate on patients with CDP was always taken with reluctance. ${ }^{7}$ The operative morbidity and mortality has been greater than in the management of other pulmonary lesions, ${ }^{78}$ and the selection of indications for operation in
CDP has been restricted by fear of the postoperative sequelae. The indications for urgent $\stackrel{\mathbb{Q}}{\mathscr{Q}}$ operation were exsanguinating haemoptysis, un- $\overrightarrow{\vec{A}}$ controlled pulmonary suppuration in patients who, despite intensive medical treatment both at the referring clinics and at Wentworth Hospital, continued to produce profuse purulent sputum and had fever, increasing anaemia, polymorpho-으 nuclear leucocytosis, and a rapidly enlarging $\underset{x}{\stackrel{\nu}{\Perp}}$ pulmonary opacity on chest radiograph; and $\overline{0}$ when the lesion might have been a bronchial carcinoma. Elective operations were confined to patients suffering a recurrence of symptoms with enlargement of the radiographic capacity at theo site of previously recognised and medically treated CDP, and when there was symptomatico

Table 3 Drug regimens in $C D P \quad$ O

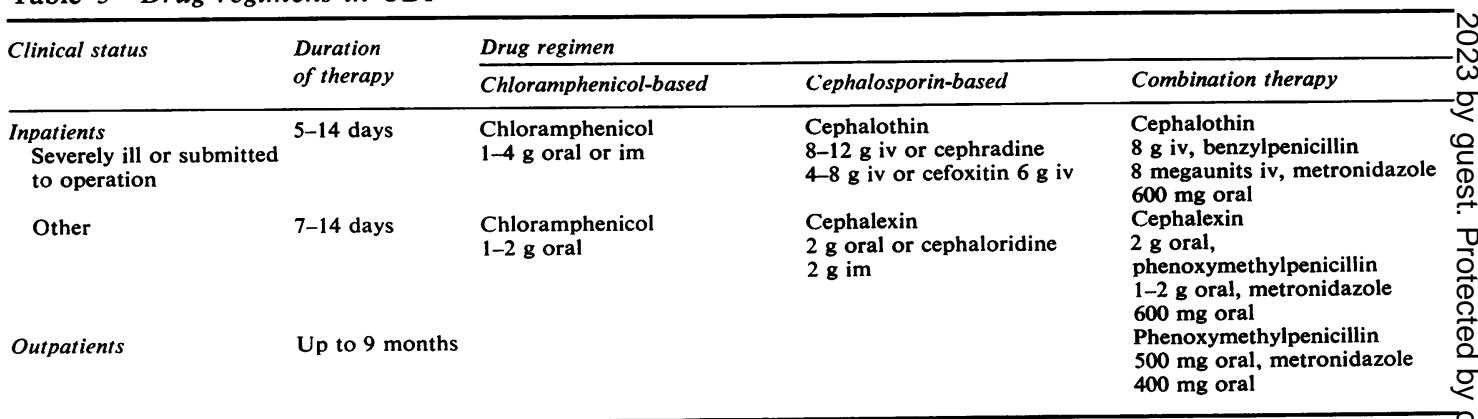

All dosages are given as daily totals for adults 
Table 4 Results of treatment of CDP

\begin{tabular}{|c|c|c|c|c|c|}
\hline Drug regimen & $\begin{array}{l}\text { Number of } \\
\text { patients }\end{array}$ & $\begin{array}{l}\text { Medical } \\
\text { treatment }\end{array}$ & $\begin{array}{l}\text { Operative } \\
\text { treatment }\end{array}$ & $\begin{array}{l}\text { Inpatient } \\
\text { deaths }\end{array}$ & $\begin{array}{l}\text { Mortality } \\
\text { rate }(\%)\end{array}$ \\
\hline $\begin{array}{l}\text { Chloramphenicol-based } \\
\text { Cephalosporin-based } \\
\text { Combination therapy }\end{array}$ & $\begin{array}{r}20 \\
429 \\
78\end{array}$ & $\begin{array}{r}98 \\
310 \\
49\end{array}$ & $\begin{array}{r}22 \\
119 \\
29\end{array}$ & $\begin{array}{r}10 \\
38 \\
1\end{array}$ & $\begin{array}{l}8 \\
8 \cdot 9 \\
1 \cdot 3\end{array}$ \\
\hline Total & 627 & 457 & 170 & 49 & $7 \cdot 8$ \\
\hline
\end{tabular}

chronic sepsis in lower lobar lesions. The results of treatment are shown in Table 4.

\section{Discussion}

There are published descriptions of infective pulmonary lesions which clinically and pathologically resemble CDP. The nomenclature of the lesions is various since they are sometimes associated with a demonstrable or inferred aetiology and sometimes with one or other part of the pneumonia-bronchiectasis-lung abscess-lung organisation complex. The best documented group of these CDP-like lesions is that in which anaerobes are incriminated as pathogens. There is also a more heterogeneous group where the aetiology is uncertain. ${ }^{9-12}$

A recent editorial in the Lancet $^{13}$ listed in historical order a series of papers, all Western in origin, associating anaerobes with pleuropulmonary disease. The gap in publication between 1946 and 1966 reflects an almost complete disappearance of CDP-like pneumonia from the West. "Deep lung rot"-a colloquialism of the 1930s and 1940s-had become a rarity whose passing was marked by the papers of Sellors et al ${ }^{14}$ Logan and Nicholson. ${ }^{15}$ Since 1966 the role of anaerobes in necrotising pneumonia, bronchiectasis, and lung abscess has been elucidated, ${ }^{16}$ and present microbiological evidence suggests that CDP belongs to this group of pulmonary disease.

If mixed aerobic and anaerobic infection is the cause of CDP as the microbiological investigation indicates, then aspiration from the mouth is the probable initiating event in the largely male population of patients where dental disease and alcohol abuse are rife. The frequent radiographic localisation of CDP lesions in the upper lobes and apical segments of the lower lobes also suggests aspiration.

Other aetiological influences such as malnutrition and vitamin deficiency are not evident and the immunological study described above has failed to demonstrate immunological deficiency (the impaired PHA response noted in six of the 20 patients is likely to be the result of the severe infection rather than its cause).
Finegold ${ }^{17}$ has listed the effective antibiotics in anaerobic infection as penicillin, cephalosporins, tetracyclines, chloramphenicol, and clindamycin. Therefore the CDP patients on the chloramphenicol and cephalosporin based regimens were not given inappropriate therapy for a mixed aerobic-anaerobic infection. However, the pathology of CDP, in particular the presence of large volumes of slough in "active" lesions and of fibrosis in "inactive", complicates treatment since such damaged lung is inaccessible to antibiotics and must lack the normal immune mechanisms. The cephalosporin, penicillin, and metronidazole combination was, therefore, introduced to counter the microbiological and pathological characteristics of CDP. The combination is bactericidal and has the theoretical advantages of in vitro effectiveness against the range of pathogens; tissue penetration, dose flexibility, and relative absence of side effects. Favourable reports have been recently published on the use of antibiotic combination therapy in mixed aerobic-anaerobic infections ${ }^{18}$ and on the empirical use of combination therapy when such infection is suspected on clinical grounds. ${ }^{19}$

It is recognised that death from pneumonia may occur despite treatment with effective antibiotics, ${ }^{20}$ and the mortality rates for certain types of pneumonia are high-25\% in necrotising pneumonia, a disease which closely resembles CDP. ${ }^{21}$ Although surgical intervention is important in the general management of anaerobic infection, ${ }^{17}$ anaerobic pulmonary disease is an exception. Contemporary opinion holds that antimicrobial therapy, physiotherapy with postural drainage, and therapeutic bronchoscopy are adequate management. Surgical drainage is rarely if ever indicated and pulmonary resection is not considered. ${ }^{13} 2122$ Nevertheless $25 \%$ of our patients have required pulmonary resection and $2 \%$ cavitary drainage because of failure of medical management to control progress of the disease and threat to life. Recognition of the importance of the anaerobic component of CDP and the consequent adjustment of antimicrobial therapy has not decreased the necessity for surgical intervention (table 4). Indeed the highest 
resection rate of $33 \%$ occurs in patients treated with the cephalosporin, penicillin, and metronidazole combination. It has been shown that combination therapy lowers the inpatient mortality rate, ${ }^{23}$ but lung destruction is not prevented and the cycle of quiescence and recurrence of CDP is not broken in many of the medically treated patients. Should the trend to lower operative morbidity and mortality continue (table 4 ), it might be correct to widen the indications for surgery to include all those of Reed and Allbritten, ${ }^{24}$ since resection is the only means of ridding the patient of damaged lung, inaccessible to antibiotics and a permanent danger to health and life.

Bacterial pneumonia is a major public health problem in tropical developing countries, ${ }^{25}$ and based on the South African experience CDP is likely to be a significant facet of this problem. However there are no reports available from these regions which are probably the world reservoirs of the disease and where it may masquerade as pulmonary tuberculosis. Prevention of CDP awaits attainment of Western standards of living and health, particularly dental, care.

This study was supported in part by grants from the Group Chairman's Fund of Anglo-American Corporation, and the South African Medical Research Council.

\section{References}

1 Le Roux BT, Dodds TC. A Second Portfolio of Chest Radiographs. Edinburgh: $\mathrm{E}$ and $\mathrm{S}$ Livingstone, 1968: 86-7.

2 Appelbaum PC, Cameron EWJ, Hutton WS, Chatterton SA, Africa CW. The bacteriology of chronic destructive pneumonia. S Afr Med J 1978; 53:541-2.

3 Altemeier WA. The cause of the putrid odor in perforated appendicitis with peritonitis. $A n n$ Surg 1938; 107:634-5.

4 Liebow AA, Hales MR, Lindskog GE. Enlargement of the bronchial arteries and their anastomoses with the pulmonary arteries in bronchiestasis. Am J Pathol 1949; 25:211-20.

5 Brain P, Cox J, Duursma J, Pudifin DJ. T and B lymphocytes in three population groups. Clin Exp Immunol 1976; 23:248-51.

6 Parker JW, Lukes RJ. A microculture method for lymphocyte transformation studies in the clinical laboratory. Am J Clin Pathol 1971; 56: 174-80.

7 Le Roux BT, Respiratory infection which requires surgical management. $S$ Afr Med J 1973; $\stackrel{\overrightarrow{\vec{S}}}{\vec{\rho}}$ 47:419-26.

8 Cameron EWJ. Surgical treatment of chronic $\frac{C}{0}$ destructive penumonia. $S$ Afr Med J 1977; 51: $\overline{\bar{c}}$

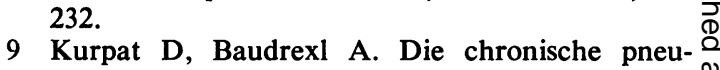
monia. Zentralbl Chir 1972; 97:457-69.

10 Boyd DHA. Failure of resolution in pneumonia. $\vec{\circ}$ Br J Dis Chest 1975; 69:259-60.

11 Cuartero AR, Jiminez FU, Redondo JP. Neu- $\vec{\omega}$ monias cronicas: comentarios sobre nueve $O$ observaciones. Rev Clin Esp 1975; 137:549-56.

12 Rzhanitsyn VV. Pathomorphology of chronic $\dot{\omega}$ bronchitis deformans in chronic unspecified or penumonia. Klin Khir 1975; 6:5-9. or

13 Editorial. Anaerobes in pleuropulmonary infec- $\omega$ tions. Lancet 1976; 1:289.

14 Sellors TH, Blair LG, Houghton LE, Thompson 은 VG, Pryce DM. Spreading suppurative pneu- monitis. Thorax 1946; 1:46-81.

15 Logan A, Nicholson H. Non-specific suppurative pneumonia. Thorax 1949; 4:125-33.

16 Finegold SM. Operation of an anaerobe labora- $\infty$ tory in a medium-sized hospital. In: Godden JO, Duncan IBR (eds). Anaerobic infections. Kalamazoo, Michigan: Upjohn E, 1974: 71.

17 Finegold SM. Therapy for infections due to anaerobic bacteria: an overview. J Infect Dis 1977; 135: supplement, S25-9.

18 Fass RJ. Treatment of mixed bacterial infections with clindamycin and gentamicin. $J$ Infect Dis 1977; 135: supplement, S76-9.

19 Bartlett JG, Miao PVW, Gorbach SL. Empiric treatment with clindamycin and gentamicin of suspected sepsis due to anaerobic and aerobic bacteria. J Infect Dis 1977; 135: supplement, 을 S80-5.

20 Austrian R. Current status of bacterial pneu- $\ddot{0}$ monia with especial reference to pneumococcal infection. J Clin Path 1968; 21: supplement 2, 93-7.

21 Meyer RD, Finegold SM. Anaerobic infections: diagnosis and treatment. South Med J 1976; 69: 1178-95.

22 Anderson CB, Marr JJ, Ballinger WF. Anaerobic infections in surgery: clinical review. Surgery N 1975; 79:313-24.

23 Cameron EWJ. The treatment of chronic $\tilde{O}$ destructive penumonia with cephalosporins, penicillin and metronidazole. $S$ Afr Med J 1978; 54:0 57-60.

24 Reed WA, Allbritten FF. The lungs: suppurative and fungal diseases. In: Gibbon JH, Sabiston DC, $\$$ Spencer FC, eds. Surgery of the chest. Second edition. Philadelphia: WB Saunders, 1969: 341.

25 Stuart-Harris CH. Pneumonia: present day experi- $\frac{}{\overparen{D}}$ ences and trends. Trans Med Soc Lond 1967; 84:27-50. 